\title{
RESPOSTAS DO CAMPO PUBLICITÁRIO ÀS PRÁTICAS DE CONTESTAÇÃO DO PÚBLICO ${ }^{1}$
}

\author{
Reponses form the advertising field to public contestation practices \\ Respuestas del campo publicitario a las prácticas de contestación del público
}

Enéias Brum

Doutorando no Programa de Pós-Graduação em Comunicação Social da Pontifícia

Universidade Católica do Rio Grande do Sul (PPGCOM/PUCRS)

brum.eneias@gmail.com

Elisa Reinhardt Piedras

Professora e pesquisadora do Programa de Pós-Graduação em Comunicação da Universidade

Federal do Rio Grande do Sul (PPGCOM/UFRGS)

elisapiedras@gmail.com

\section{Resumo}

Este artigo tem objetivo de explorar repercussões de práticas de contestação ao campo publicitário no contexto mercadológico (agências e anunciantes) e no cenário regulador (Conselho de Autorregulamentação Publicitária - CONAR). A discussão teórica aborda a publicidade como campo articulado ao mundo social e às práticas cotidianas dos sujeitos, entre elas, as práticas de contestação. A metodologia da pesquisa é qualitativa com recursos complementares de quantificação e envolve a técnica de análise documental sobre dados relativos ao contexto brasileiro no período 2011-2019, disponíveis em portais de notícias especializadas em comunicação e no site do CONAR. Os resultados apontam manifestações reativas e empáticas por parte de anunciantes e de agências de publicidade; bem como as ações de sustações, alterações, advertências e arquivamento promovidas pelo CONAR.

Palavras-chave: Publicidade e propaganda. Práticas de contestação. Produção publicitária.

\section{Abstract}

This article aims to explore the repercussions of public contestation practices to the advertising field in the market context (advertisers and agencies) and in the regulatory scenario (Advertising Self-Regulation Council - CONAR). The theoretical discussion approaches advertising as an field articulated with the social world and the people's daily practices, among them, the contestation practices. The methodology research is qualitative with complementary quantitative resources and involves the documental analysis technique on data about Brazilian context from the years 2011 to 2020, available on news websites specialized in communication and on the CONAR`s website. The results point to reactive and

\footnotetext{
${ }^{1}$ Essa pesquisa foi realizada com apoio da Coordenação de Aperfeiçoamento de Pessoal de Nível Superior Brasil (CAPES). A investigação foi desenvolvida junto ao grupo de pesquisa Comunicação e Práticas Culturais (PPGCOM/UFRGS), no âmbito do projeto "Rumos da pesquisa em publicidade".
} 
empathic manifestations by advertisers and advertising agencies; they also show the actions of withdrawals, alterations, warnings and discontinuing promoted by CONAR.

Key words: Advertising. Contestation practices. Advertising production.

\section{Resumen}

Este artículo tiene como objetivo explorar las repercusiones de las prácticas de contestación al campo publicitario en el contexto del mercado (agencias y anunciantes) y en el escenario regulatorio (Consejo de Autorregulación Publicitaria - CONAR). La discusión teórica aborda la publicidad como campo articulado al mundo social y prácticas cotidianas de los sujetos, entre ellas, las prácticas de contestación. La metodología de investigación es cualitativa con recursos complementarios de cuantificación y involucra la técnica de análisis de documentos sobre el contexto brasileño en el período 2011-2019, disponibles en portales de noticias especializados en comunicación y en el sitio web de CONAR. Los resultados muestran manifestaciones reactivas y empáticas por parte de anunciantes y agencias de publicidad; así como las acciones de retiros, alteraciones, avisos y cierres promovidas por CONAR.

Palabras clave: Publicidad y propaganda. Prácticas de contestación. Producción publicitaria.

\section{INTRODUÇÃO AO TEMA E REFERÊNCIAS TEÓRICAS}

Neste artigo, abordamos a publicidade e propaganda com especial interesse nas práticas de produção publicitária e sua articulação ao mundo social e às práticas de contestação de receptores em oposição ao conteúdo de anúncios publicitários. O objetivo da pesquisa é explorar as repercussões de práticas de contestação ao campo publicitário no contexto mercadológico (agências e anunciantes) e no cenário regulador (Conselho de Autorregulamentação Publicitária - CONAR) entre 2011 e 2019 no Brasil.

Justificamos a investigação, no âmbito acadêmico, por colaborar com o avanço do conhecimento científico sobre a produção publicitária, principalmente no que diz respeito a repercussões da interação espontânea de receptores (PIEDRAS; WOTTRICH, 2017). Como contribuição social, promovemos reflexões sobre as dinâmicas geradas pelos tensionamentos entre receptores e produtores que ampliaram sua visibilidade recentemente. Além disso, acreditamos que a investigação pode gerar frutos a partir da disseminação de possíveis e necessárias melhorias na relação entre o público e os anunciantes.

Em diálogo com estudos antecedentes, na discussão teórica, tratamos das noções de campo publicitário (PETERMANN, 2011; WOTTRICH, 2019), articulação da publicidade com o mundo social (PIEDRAS, 2009; 2011) e práticas de contestação à publicidade (WOTTRICH, 2019).

Petermann (2011) e Wottrich (2019) abordam a publicidade na perspectiva do campo, viabilizando que seja interpretado a partir de suas lógicas internas, mas explicado a partir do contexto social no qual se inserem suas práticas. As autoras analisam o campo publicitário 
como integrante do campo midiático, que viabiliza aos agentes de outros campos sociais o acesso à esfera pública e os auxilia na construção da percepção de relevância na sociedade. ${ }^{2}$ Considerar as disputas por posições de poder que ocorrem na articulação com as forças econômicas, políticas e culturais e dentro das práticas dos atores amplia a possibilidade de chegarmos a definições não estanques sobre o campo publicitário. Os limites definidos pelas relações entre as práticas dos sujeitos e a estrutura que os cerca são variáveis e suscetíveis a mudanças provocadas, inclusive, pela própria relação entre os campos (PETERMANN, 2011; WOTTRICH, 2019). A natureza de intermediação das forças econômicas, políticas e culturais condiciona a forma como o campo publicitário se constrói. Sua narrativa se vale de acontecimentos e linguagens "[...] de outros campos sociais como matéria-prima para seus anúncios e assim seus discursos são perpassados por uma quantidade infindável de outros, provindos de diversos lugares" (PETERMANN, 2011, p. 85).

As relações da publicidade com o mundo social são abordadas por Piedras (2009) a partir da noção de articulação (HALL, 1980; 1985; 1997; 2003) para questionar a dicotomia entre perspectivas deterministas econômicas ou idealistas culturais da análise social: "mais que um processo comunicativo condicionado por uma estrutura social histórica, ela [a publicidade] é um sistema que articula sua produção com as práticas cotidianas dos sujeitos" (PIEDRAS, 2009, p. 25). Se por um lado o sistema hegemônico capitalista e a cultura do consumo são favorecidos pela publicidade, sobretudo por sua articulação às forças econômicas, também é possível afirmar que sua permeabilidade com o campo cultural proporciona emergência de movimentos e mudanças sociais cedendo, assim, visibilidade para o contra-hegemônico em suas práticas.

Essa articulação pode ser o ponto de partida para mudanças nas condições estruturantes a partir da relevância da publicidade na formação da cultura contemporânea e da ressignificação de sentidos compartilhados por indivíduos cujo discurso esteja socialmente invisibilizado pela comunicação midiática. Piedras (2011, p. 11) considera as possibilidades que sujeitos insatisfeitos têm de tensionar o campo publicitário em um movimento que "não precisa necessariamente passar por grupos organizados e instituições, e pode afetar o conteúdo das produções midiáticas já que amplia a força dos vetores sociais de pressão sobre elas".

\footnotetext{
${ }^{2}$ Ambas partem da noção de campo social, de Pierre Bourdieu. Petermann usa o termo campo da publicidade e Wottrich emprega a expressão campo publicitário. O presente texto utiliza a forma campo publicitário a fim de unificar sua apresentação.
} 
Wottrich (2019) aprofunda o olhar sobre esses tensionamentos ao observar as semelhanças entre as dimensões temáticas tratadas pelos contestadores e pelo campo publicitário. Ao analisar "as modalidades de participação dos receptores orientadas a subverter ou minar as lógicas do campo publicitário, realizadas a partir do contato com os anúncios", a autora aponta para cinco características das "práticas de contestação" (WOTTRICH, 2019, p. 201-2). Questões sensíveis historicamente presentes na relação entre o campo publicitário e os âmbitos político e institucional são trazidas pelos receptores à sua relação com agências e anunciantes e, por isso, são geradas e geradoras de tensionamentos. Frente a uma publicidade historicamente carregada de estereótipos, a maior parte das contestações tem como foco "a objetificação das mulheres nos anúncios e o estímulo a comportamentos discriminatórios em relação a elas" (WOTTRICH, 2019, p. 271), e, por isso, tematizam gênero e buscam reconhecimento identitário. Publicizadas por indivíduos na internet, as contestações se tornam coletivas pela sua capacidade de levantar pautas percebidas como problemáticas na publicidade a ponto de convertê-las em assuntos de interesse público e se tornarem midiáticas ao serem noticiadas pela imprensa especializada.

Para obter uma visão abrangente sobre as contestações à publicidade, Wottrich (2019) debruçou-se sobre os dados publicados pelo órgão regulador da publicidade brasileira, o Conselho Nacional de Autorregulamentação Publicitária - CONAR.

Reconhecido desde 1980 pelo mercado, governo e sociedade civil como a entidade máxima do campo publicitário, a função do CONAR é de "zelar pela liberdade de expressão comercial e defender os interesses das partes envolvidas no mercado publicitário, inclusive os do consumidor" (CONAR, 2021). A entidade possui, além do Conselho Superior, um Conselho de Ética, composto por vinte e quatro representantes da sociedade civil, sessenta e seis representantes de associações representativas de agências, anunciantes e veículos, oito profissionais de criação e até doze representantes de entidades aderentes selecionadas pelo Presidente do CONAR. É o Conselho de Ética que julga e delibera sobre os processos investigativos ou contenciosos que podem ser iniciados somente por grupos formados por consumidores e por indivíduos membros e associados ao CONAR, não cedendo essa possibilidade a entidades, associações e até ao próprio governo. Para isso, o Conselho se orienta pelo Código de Brasileiro de Autorregulamentação Publicitária, cujo texto define e conceitua os 12 Princípios Gerais que devem ser seguidos por anúncios, entre os quais 
apresentação verdadeira, adequação às leis, respeitabilidade, identificação publicitária, responsabilidade social e cuidado com o público infantil (CONAR, 2021). ${ }^{3}$

Diante de uma denúncia, há quatro decisões previstas no Código: sustação, quando o Conselho publica a recomendação aos veículos no sentido de que interrompam a divulgação do anúncio; alteração ou correção, para anúncios cujas infrações podem ser mitigadas com algumas mudanças, segundo avaliação do CONAR; advertência, em que é salientada a necessidade de revisão da conduta ética do anunciante; e arquivamento, quando a denúncia é considerada improcedente.

Ao analisar o resultado das 1147 deliberações publicadas entre 2005 e 2015 pelo CONAR, Wottrich (2019) identificou a existência de cinco dimensões temáticas de tensionamentos: comportamento, linguagem, produtos, públicos e veracidade. Posteriormente, analisando as pautas presentes em 114 edições de periódicos de organizações representativas do campo publicitário publicados no mesmo período (Associação Brasileira das Agências de Publicidade, Associação Brasileira de Anunciantes, CONAR, Conselho Executivo de Normas-Padrão e Grupo de Mídia de São Paulo), a autora identificou as mesmas dimensões temáticas sendo tratadas pela ótica dos produtores de publicidade e destacou a existência de três temas de tensionamentos mais recorrentes entre a publicidade brasileira contemporânea e seus receptores: crianças e adolescentes, bebidas alcoólicas e politicamente correto. ${ }^{4}$

O diálogo com essas pesquisas antecedentes e o cenário mercadológico nos encaminha o presente artigo diretamente para a orientação metodológica da pesquisa, que apresentamos a seguir.

\section{PROCEDIMENTOS METODOLÓGICOS}

A metodologia da pesquisa é qualitativa (FLICK; GIBBS, 2009) devido ao interesse em explorarmos a diversidade e variedade de movimentos emergentes de articulação entre práticas de produção e de contestação. Nos procedimentos, partimos da técnica de análise documental que, além de viabilizar a localização, identificação e organização de documentos, funciona "como expediente eficaz para contextualizar fatos, situações e momentos" (MOREIRA, 2005, p. 276).

\footnotetext{
${ }^{3}$ Esses seis princípios destacam-se por somarem $87 \%$ das representações abertas em 2018, segundo o site do CONAR.

4 As principais contestações são: em crianças e adolescentes, estímulo ao consumo junto a um público considerado vulnerável; em bebidas alcoólicas, estímulo ao consumo excessivo e discriminação a mulheres; em politicamente correto, situações de discriminação e desrespeito com grupos identitários (WOTTRICH, 2019).
} 
Em função do interesse em analisar repercussões, nas práticas de produtores e no cenário regulador, de contestações do público com visibilidade midiática (WOTTRICH, 2019), realizamos um mapeamento relativo ao contexto brasileiro a partir de dois tipos de fontes: (1) uma para identificar manifestações dos anunciantes e publicitários diante de contestações a campanhas; e (2) outra para conhecer as deliberações do setor regulador (CONAR) sobre essas situações.

A primeira fonte de dados são os portais na internet de veículos especializados em comunicação publicitária: Mundo do Marketing, Portal da Propaganda, AdNews, Meio \& Mensagem e Propmark ${ }^{5}$. No campo de busca interna dos portais, foram pesquisadas palavraschave relacionadas a contestações em campanhas publicitárias; práticas de gestão em agências de publicidade e anunciantes; e ações para ampliação da diversidade na publicidade. Delimitamos o avanço de, no máximo, dez páginas de resultados nas buscas internas dos portais e, assim, incluímos a quase totalidade das notícias relatando campanhas contestadas pelo público. Tal procedimento gerou um recorte temporal, contemplando o período de 2011 a 2019, que oportunizou um olhar em perspectiva sobre o fenômeno ao longo de uma década.

A segunda fonte de dados é o site do (CONAR). No campo de busca interna do site, pesquisamos a ocorrência de julgamentos de cada uma das campanhas identificadas anteriormente, na coleta através da mídia especializada.

A partir dessa coleta, descrevemos os dados de forma sistemática contemplando: nomes das campanhas, anunciantes, agências de publicidade, motivação das contestações, manifestações dos anunciantes, manifestações das agências, decisão do CONAR. Disso resultou um mapeamento realizado nos portais de veículos especializados em publicidade no qual identificamos 60 campanhas contestadas pelo público no período entre 2011 e 2019. Entre elas, 34 situações contavam com manifestações formais dos produtores e 27 foram julgadas pelo CONAR. Para realizar a análise transversal dos dados obtidos, adotamos orientação qualitativa complementada pela quantificação - conforme fundamentado na discussão teórica - o que permitiu contemplar: (1) o posicionamento adotado por agências e anunciantes através das manifestações públicas assinadas pelos profissionais envolvidos na produção das campanhas contestadas; e (2) o teor das deliberações do CONAR sobre esses casos, bem como a relação entre as práticas de contestação à publicidade e as decisões tomadas pelo Conselho com base no Código de Ética.

\footnotetext{
${ }^{5}$ Cinco portais indicados na primeira página do buscador Google conforme relevância de conteúdo na busca por "notícias sobre publicidade".
} 
Apresentamos tais resultados a seguir, a começar pelas manifestações de anunciantes e agências, seguidas do olhar do CONAR sobre as campanhas e pautas das contestações.

\section{MANIFESTAÇÕES DE PROFISSIONAIS DE EMPRESAS ANUNCIANTES E AGÊNCIAS: REATIVAS E EMPÁTICAS}

Ao analisar as declarações formais das marcas anunciantes e agências de publicidade ${ }^{6}$ nas notícias de veículos especializados em publicidade a respeito de campanhas contestadas, observamos manifestações de dois tipos: reativas ou empáticas, sendo a primeira mais significativa quantitativamente que a segunda (respectivamente, 23 e 11 situações).

As manifestações reativas de produtores contemplam: compromisso da marca com a diversidade; argumentações explicitamente discordantes das contestações; ações publicitárias em resposta às contestações; explicações técnicas; e satisfação com debate em torno da campanha.

As manifestações empáticas de produtores contemplam: pedidos de desculpas seguidos de interrupção da campanha; pedidos de desculpas acrescentados de alegações de ruídos na comunicação a serem solucionados com novas peças publicadas; e um caso de exceção que gerou embate interno no campo publicitário.

Essas manifestações, que reverberam midiaticamente na imprensa especializada em publicidade, dialogam com os resultados de Wottrich (2019), que observou as repercussões das práticas de contestação em publicações de entidades representativas do campo publicitário. Tais situações nos permitem compreender a natureza dos movimentos do campo publicitário através de um olhar mais próximo das perspectivas que orientam as práticas de produção dos profissionais. A seguir, apresentamos a análise das respostas dos produtores juntamente às motivações das contestações e ao relato de uma situação representativa para cada postura adotada pelo campo.

\subsection{Manifestações reativas: declarações contrárias às contestações}

Entre as manifestações reativas de produtores, destacamos a afirmação do compromisso da marca com a diversidade. Elas são decorrentes de contestações sobre diversidade de representações identitárias nos anúncios, partindo de indivíduos com duas

\footnotetext{
${ }^{6}$ Salienta-se que a responsabilização legal e ética pela publicidade é das empresas anunciantes e de que a maior parte das declarações encontradas foi concedida por anunciantes. Entretanto, o relato destaca especificidades de declarações dadas por anunciantes ou por publicitários em situações em que (a) foram encontradas declarações de ambos os agentes e (b) houve divergência entre as posturas adotadas.
} 
posturas distintas: de um lado, pessoas contrárias à representação de diversidade, de outro, sujeitos insatisfeitos com a ausência de diversidade nas campanhas.

As contestações à representação de diversidade são promovidas por pessoas que se queixam de campanhas que incluem pessoas negras como protagonistas, contrariam padrões heteronormativos e/ou combatem preconceito LGBTQIA+. ${ }^{7} \mathrm{O}$ filme de Dia dos Namorados de O Boticário (2015) recebeu críticas por apresentar uma troca de presentes e abraços entre um casal de homens e um casal de mulheres homossexuais (além de um casal heterossexual formado por pessoas com idades diferentes e outro casal sem nenhum marcador social aparente). A exemplo dos demais produtores que se posicionaram em favor da diversidade quando contestados, O Boticário afirmou que "valoriza a tolerância e respeita a diversidade de escolhas e pontos de vista", e foi apoiado pela agência AlmapBBDO, que considerou positiva a repercussão gerada em torno do filme (MORAES, 2015, documento eletrônico).

O compromisso com a diversidade também foi argumento de anunciantes frente a apontamentos de que suas campanhas excluíam identidades através das práticas de machismo, gordofobia, racismo e/ou preconceito de classe. A marca Perdigão recebeu contestações que apontavam discriminação racial em seu filme de Natal (2019). O anúncio apresentava dois cenários marcados pela diferença de classe e representava a classe alta com uma família branca e a classe baixa com uma família negra. Em nota divulgada na imprensa especializada, o anunciante afirmou: "falar de generosidade é, para nós, uma forma de união e agradecimento a todos os nossos consumidores, que há três anos colaboram para o Natal de mais de 6 milhões de pessoas, independente de cor, gênero, raça ou religião. É nisso que acreditamos" (MONTEIRO, 2018, documento eletrônico). Meses depois, a parceria com a agência DM9DDB foi encerrada (MACEDO, 2019).

Outro padrão de manifestação reativa contempla situações em que os produtores respondem às contestações com argumentações explicitamente discordantes das contestações. As manifestações contrárias às campanhas abordam sexismo, discriminação racial e/ou ausência de diversidade na publicidade. Entre as situações identificadas, a marca de roupas íntimas femininas Hope declarou-se contrária à percepção do público de que teria sido machista em duas ocorrências. A primeira campanha referenciada (2011) se propunha a ensinar às mulheres que a forma correta de contar um assunto desagradável ao seu marido é usando roupas íntimas. Frente às contestações, o anunciante declarou: "seria absurdo se nós,

\footnotetext{
7 Lésbicas, gays, bissexuais, transexuais, queer, intersexuais, assexuados e todas as demais classificações possíveis relacionadas à sexualidade que fogem dos padrões heteronormativos.
} 
que vivemos da preferência das mulheres, tomássemos qualquer atitude que desvalorizasse nosso público consumidor" (HOPE, 2016, documento eletrônico). Na segunda contestação identificada (2014), a campanha apresentava locução de um filho aceitando dinheiro para não revelar, à sua mãe, comentários de seu pai a respeito do corpo da atriz Juliana Paes. A marca defendeu-se das críticas afirmando que o conteúdo da campanha não estimulava má conduta "por se tratar de uma situação exacerbada e de um diálogo inverossímil e caricato" (ARAUJO, 2016, documento eletrônico).

Ações publicitárias em resposta às contestações foi expediente utilizado em campanhas que tiveram retornos negativos do público a respeito de abordagens consideradas machistas e/ou imorais. Como exemplo, a campanha da marca de móveis Alezia foi contestada por recorrer a imagens de modelos de biquíni na beira da praia, objetificando o corpo feminino para apresentar seus produtos de maneira descontextualizada. Diante das avaliações negativas do público na página no Facebook, a marca manifestou-se de modo contrário aos argumentos dos contestadores, além de convocar seus seguidores para uma espécie de batalha na qual, se conseguissem um número de avaliações positivas maiores do que as negativas registradas pelos críticos à marca, realizariam uma doação em dinheiro para entidade de apoio a crianças com deficiência física (MARCA, 2016).

Explicações técnicas também foram utilizadas em manifestações reativas de produtores diante de contestações sobre publicidade enganosa e/ou racismo. Uma das situações em que o público apontou preconceito racial ocorreu quando a campanha de lançamento de papel higiênico na cor preta da marca Personal fez uso da frase Black Is Beautiful - historicamente utilizada na luta por direitos sociais e reconhecimento identitário da população negra. Diante disso, a agência Neogama e o anunciante assinaram um comunicado conjunto afirmando que o conceito criativo não associava a campanha ao movimento negro. Segundo os produtores, a intenção era ressaltar a cor preta "selecionada com o objetivo de destacar um produto que segue tendência de design já existente no exterior e trazida pela Santher para o Brasil. Nenhum outro significado, que não seja esse, foi pretendido" (DEPOIS, 2017, documento eletrônico).

Manifestações reativas de produtores que se consideraram satisfeitos com o debate gerado a partir de campanhas contestadas remetem a apenas duas situações. A campanha do Comitê Paralímpico Brasileiro (2016) foi contestada pela exclusão de verdadeiros atletas portadores de deficiência (pois usou recursos de tratamento de foto em atores que não possuem deficiência física, para representá-los sem um braço e uma perna), e diante disso o 
anunciante afirmou que o objetivo de gerar reflexão havia sido alcançado (10 FATOS, 2016). Uma publicação no Facebook da marca de uísque Johnnie Walker (2016) foi contestada pelo público, que a considerou racista ao usar a foto de um negro sobreposta pela palavra "branco" acompanhada da legenda "E você? Ainda deixa usarem sua origem como obstáculo para o seu progresso? Racismo. Até quando?" (supondo permissividade de negros a atitudes que dificultam seu avanço social). A marca respondeu a todos os comentários feitos pelo público na postagem de maneira padrão, desconsiderando apelos ao diálogo, com um texto no qual dizia que as manifestações provavam que "o racismo é um tema que merece ser debatido de forma séria e respeitosa por todos até que seja uma coisa do passado" (POST, 2016, documento eletrônico).

\subsection{Manifestações empáticas: concordância declarada às contestações}

Entre as manifestações empáticas de produtores, destacamos os pedidos de desculpas dos anunciantes seguidos da interrupção da campanha frente a contestações que declaravam identificar machismo, sexismo e/ou desrespeito. Além dessas motivações, o uso de estereótipos foi apontado em um filme da marca de automóveis Renault (2017), no qual pessoas naturais do nordeste brasileiro eram chamadas de preguiçosas. Frente a um grande número de reclamações nas redes sociais da marca no dia de lançamento do filme, a empresa interrompeu sua veiculação em menos de 24 horas e afirmou que a empatia ao público havia motivado a tomada de decisão "em respeito às pessoas que se sentiram ofendidas com o material [...]" (SACCHITIELLO, 2017, documento eletrônico). Nesse grupo de situações todas contestações tiveram sucesso em conquistar a atenção dos anunciantes, gerar retratações públicas e o término de veiculações de conteúdos que consideravam nocivos. Entretanto, ressaltamos que, junto aos pedidos de desculpa direcionados a possíveis ofendidos, os produtores dessas campanhas afirmaram haver equívocos na interpretação das intenções do discurso publicitário e que a marca não pretendia ser desrespeitosa ou danosa.

Há situações de manifestações empáticas em que os produtores reconhecem as contestações, as atribuem a ruídos na interpretação do público (como as citadas acima), mas acrescentam a afirmação de que novas peças esclareceriam o posicionamento da marca frente a apontamentos de racismo e/ou machismo. A marca Skol, ao veicular a campanha de mídia externa no carnaval "Esqueci o Não em Casa" (2015), foi contestada inicialmente por duas mulheres que afirmaram, em publicações que repercutiram amplamente nas redes sociais, que a marca estaria incentivando assédio e comportamento abusivo. A marca 
respondeu, publicamente, que não havia intenção ofensiva, que a tangibilização havia sido incompreendida e declarou: "[...] por respeito à diversidade de opiniões, substituiremos as frases atuais por mensagens mais claras e positivas, que transmitam o mesmo conceito" (LEITE, 2015a). Entretanto, percebemos que as peças divulgadas não correspondiam à suposta intenção original, com textos como "Não deu jogo? Tire o time de campo", acompanhadas do subtítulo "Nesse carnaval, respeite". Embora o anunciante tenha afirmado que a campanha seria mais bem compreendida com a veiculação de novas peças publicitárias, o tom dado aos anúncios parece dialogar diretamente com as contestações realizadas na tentativa de amenizar as críticas (LEITE, 2015b).

Uma situação excepcional revela a possibilidade de contestações do público serem geradoras de embates internos no campo publicitário. Um anúncio do produto Aspirina (2016), cujo título era "Calma amor, não estou filmando isso.mov", foi contestado por comparar um caso de gravação de ato sexual sem consentimento a uma simples dor de cabeça. A Bayer, empresa anunciante responsável pela marca, declarou que a peça havia sido uma iniciativa da agência AlmapBBDO para inscrição em premiação internacional, mas que não teria sido veiculada. Em seguida, a agência declarou: "A AlmapBBDO lamenta que o anúncio de Aspirina, do nosso cliente Bayer, tenha causado constrangimentos e esclarece que não houve a intenção de tratar com indiferença abusos de qualquer natureza" (ALMAPBBDO, 2016, documento eletrônico). Complementarmente, as premiações obtidas com as peças foram devolvidas.

Diante desses dados, fica explícito que, mesmo quando os produtores manifestam-se de modo empático, inclusive com pedido de desculpas, as ressalvas em suas declarações ainda os posicionam como defensores das marcas, sem reconhecer totalmente a pertinência das argumentações presentes nas práticas de contestação do público.

\section{AÇÕES DO CONAR: SUSTAÇÕES, ALTERAÇÕES, ADVERTÊNCIAS E ARQUIVAMENTOS}

No mesmo contexto em que circulam as práticas de contestação do público (Wottrich, 2019) e as manifestações públicas de profissionais das marcas anunciantes e agências de publicidade (sejam elas reativas ou empáticas), está em cena outro agente do campo que tem o papel regulador, o CONAR. No período de 2011 a 2019, das 60 campanhas contestadas pelo público que identificamos na pesquisa, 27 foram julgadas pela entidade, cujas ações 
culminaram em sustações, alterações, advertências e arquivamentos conforme apresentamos a seguir.

Há situações em que o CONAR alinha-se às contestações do público, em julgamentos que deliberam a sustação e interrupção de veiculação. Nessas evidências empíricas, constatamos denúncias motivadas por desconforto do público em relação a questões de gênero, discriminação racial e/ou infração nas regras para anúncios de bebidas alcoólicas. Uma das situações em questão é o filme da marca Novalfem (2015) que continha música cantada por Preta Gil tratando dores provocadas pela cólica menstrual como "mimimi", expressão comumente utilizada para menosprezar o ato de alguém se queixar de algo. Criticada por mulheres nas redes sociais e denunciada ao CONAR, a contestação foi acolhida pelo CONAR em forma de sustação, baseada em princípios de "respeitabilidade" do Código de Ética, como o artigo que determina que "nenhum anúncio deve favorecer ou estimular qualquer espécie de ofensa ou discriminação de qualquer natureza" (CONAR, 2021, documento eletrônico). Antes do resultado do julgamento, contudo, o anunciante declarou considerar a opinião das pessoas ofendidas para reconsiderar a campanha e, depois, cancelou as ações que estavam programadas para sua continuidade (OLIVEIRA, 2015a; CONAR, 2021).

Na mediação entre público e produtores, por vezes o julgamento do CONAR delibera a recomendação de alteração. Nessas situações, há denúncias motivadas pela percepção de que há, nas campanhas, preconceito racial ou regional, desrespeito com animais, bem como estímulo ao consumo de bebida alcoólica. A marca de azeites Gallo (2011), por exemplo, publicou anúncio considerado de cunho racista por um grupo de consumidores em função do título "nosso azeite é rico. o vidro escuro é o segurança" (CONAR PEDE, 2016). Assim como Novalfem, citada acima, a campanha foi julgada tendo em vista os princípios de "respeitabilidade". Embora o caso possa ser considerado emblemático de um estereótipo racista vigente na sociedade brasileira, não foi visto dessa forma pelos conselheiros que "[...] seguiram o voto do relator, que julgou não haver no anúncio intenção racista, mas ponderou que ele permite tal interpretação e que a comunicação não deve dar margem a associações equivocadas, pela responsabilidade social que tem", em uma referência indireta ao artigo 20 do Código que pontua que "toda atividade publicitária deve caracterizar-se pelo respeito à dignidade da pessoa humana, à intimidade, ao interesse social" (CONAR, 2021, documento eletrônico). Sem admitir a percepção de que a frase reforça a discriminação contra pessoas negras, a posição do CONAR acabou por embasar manifestações defensivas da agência 
responsável pela criação. A AlmapBBDO afirmou que o anúncio "não foi considerado racista, porém pode dar margem a outras interpretações" e ressaltou que a veiculação da peça já havia sido encerrada um ano antes do julgamento, não havendo intenção de voltar à mídia (CONAR PEDE, 2016).

Outras situações, mais confortáveis para os produtores, são aquelas em que o julgamento do CONAR delibera a advertência. Nessa seara, encontramos infrações técnicas ao código de ética no que diz respeito a omissão, exagero ou ambiguidade de anúncios, tais como a não identificação de conteúdo publicitário ou falta de capacidade comprobatória de informações veiculadas. Além disso, entre os dados analisados, os alvos das contestações não eram marcas de empresas anunciantes, mas perfis de redes sociais de pessoas públicas, como a influenciadora digital Gabriela Pugliesi (2019) que descreveu supostos benefícios medicinais do chá Desinchá, sem que houvesse comprovação de tais efeitos (SACCHITIELLO, 2019a), como determina o anexo H do Código de Ética ao obrigar marcas de bebidas a comunicar propriedades funcionais baseando-se em "dados fáticos, técnicos ou científicos" (CONAR, 2021, documento eletrônico). ${ }^{8}$

Por fim, há denúncias sobre as quais o CONAR delibera o arquivamento, envolvendo anúncios contestados sob alegação de objetificar o corpo feminino, diminuir do papel da mulher na sociedade e instigar atitudes machistas, praticar racismo e/ou estimular o consumo infantil. Consideramos a deliberação mais representativa entre os dados analisados, o que revela a posição da entidade de resguardar os produtores e distanciar-se da expectativa do público. ${ }^{9}$ Os relatos dessas decisões não revelam os artigos do Código ativados no julgamento, limitando-se a citar o artigo que baseia o arquivamento quando o Conselho “julgar não caracterizada infração" (CONAR, 2021, documento eletrônico). Como ilustração, analisamos a denúncia realizada por grupo de consumidores que considerou o filme de Dia da Mulher da marca Riachuelo (2014) racista. Na peça, uma mulher branca é vestida por uma personagem negra que, por sua vez, é invisibilizada por ter somente suas as mãos enquadradas na imagem. Mesmo com o anunciante acatando os protestos e interrompendo a veiculação do filme, o CONAR decidiu pelo arquivamento da denúncia e reproduziu, no relato do julgamento, os argumentos de defesa do anunciante "[...] considerando que os anúncios

\footnotetext{
${ }^{8}$ Mesmo não havendo provas concretas da existência de vínculo comercial das influenciadoras, as empresas responsáveis pelas marcas em questão foram advertidas pelo Conselho sobre o não cumprimento das regras da profissão.

${ }^{9}$ Entre os 27 casos apreciados pelo Conselho presentes no estudo, a maior parte - 15 anúncios - resultaram em arquivamento da denúncia.
} 
apenas expõem de forma artística a força e os encantos das mulheres brasileiras" (CONAR, 2020).

\section{CONSIDERAÇÕES FINAIS: CONTESTAÇÕES ENTRE MANIFESTAÇÕES E AÇÕES}

Cada campanha possui características únicas, com diferentes contextos e atores envolvidos, abordagens publicitárias, contestações e repercussões distintas. Ao agrupar casos e buscar elementos de comparação, não pretendemos apontar regras ou padrões a serem seguidos nas práticas de produção publicitária (PIEDRAS, 2019). Porém, os resultados auxiliam a observar a natureza dos movimentos de agências e anunciantes que já vivenciaram práticas de contestação (WOTTRICH, 2019).

Os dados que apresentamos explicitam a articulação entre a posição ocupada pelo público e o campo publicitário. Trata-se de um espaço de disputa (PETERMANN, 2011; WOTTRICH, 2019), em que o público provoca a produção (PIEDRAS, 2011), que reage através de manifestações, quase sempre assinadas por profissionais das empresas anunciantes e agências envolvidas. A produção reage, destacamos, pois não assume a iniciativa de prevenir ou evitar as contestações, apenas responde a elas. Essa resposta, publicizada e midiatizada, tende mais ao confronto, e menos a empatia. Mesmo quando o caminho é o da empatia, desqualifica o olhar do público em favor de uma defesa cega das marcas. O embate entre o público e as marcas segue, paradoxalmente, rentabilizado pelas marcas.

Enquanto isso, uma parte das contestações do público assume a formalização de denúncias junto à entidade reguladora do setor. No CONAR, entre as possibilidades de contemplar os ofendidos e perdoar os ofensivos, através de sustações e alterações, prevalecem a advertência e o arquivamento, fundamentadas no argumento de defender interesses mútuos e a liberdade de expressão comercial (CONAR, 2021). Na relação entre liberdade e interesses, a expressão é de quem?

O sistema de autorregulamentação é construído de maneira que não se deixa ser acessado por entidades ou pelo governo (CONAR, 2021) e as decisões do CONAR são, na maioria das vezes, dissonantes das expectativas do público. As manifestações de produtores evidenciam desapreço à opinião do público e possuem ressalvas nos pedidos de desculpas. Esses são traços que demonstram que a postura defensiva e protecionista está presente. Mesmo quando o campo publicitário parece ter sido sensibilizado pelas contestações. Se, conforme Wottrich (2019), as práticas de contestação visam a gerar mudanças nas práticas de 
produção da publicidade, as interrupções de veiculação podem ser vistas como ações táticas a serviço de estratégias que não alteram estruturalmente o campo publicitário.

Entretanto, na dupla articulação da publicidade, abordada por Piedras (2009), as práticas estruturadas são o ponto de partida para novas gerações de práticas. Sob essa perspectiva, propomos dois caminhos para qualificar as investigações sobre movimentações das práticas de produção publicitária motivadas pela articulação às práticas de contestação.

A primeira é aprofundar a análise sobre as propostas de atuação publicizadas nas manifestações dos produtores, ações efetivamente implementadas e possíveis resultados obtidos. Nesse sentido, ao longo da investigação aqui apresentada, tivemos dois achados inesperados: (1) implementações de programas para ampliar a presença de sujeitos pertencentes a minorias sociais em agências de publicidade e (2) iniciativas autônomas de profissionais do campo publicitário pró-diversidade na publicidade brasileira. Foram encontrados programas e iniciativas relativas a questões de gênero, raciais e LGBTQIA+ tratadas de maneira individual ou interseccional. Avançar a análise e discussão sobre esses dados pode proporcionar perspectivas sobre a mobilidade ou imobilidade do campo na relação com as contestações que sofre.

Também é possível obter novos olhares para a discussão acessando pontos de vista de profissionais que tenham vivenciado práticas de contestação. Para se diferir da coleta de declarações concedidas à imprensa especializada e buscar maior clareza sobre as repercussões posteriores às contestações, a realização de entrevistas individuais surge como alternativa.

Portanto, consideramos necessárias e oportunas novas investigações sobre práticas de produção para compreender se os movimentos iniciais das agências e anunciantes são geradores de repercussões mais profundas e longevas na condução das estratégias de comunicação desenvolvidas pelo campo publicitário.

\section{REFERÊNCIAS}

10 FATOS que marcaram a propaganda em 2016. Adnews, [s.1.], 14 dez. 2016. Disponível em: https://Adnews.com.br/adpublicidade/10-fatos-que-marcaram-propaganda-em-2016. Acesso em: 23 out. 2019.

ALMAPBBDO abre mão de Leões de Bronze após polêmica. Adnews, [s.1.], 24 jun. 2016. Disponível em: https://adnews.com.br/almapbbdo-abre-mao-de-leoes-de-bronze-apospolemica. Acesso em: 21 out. 2019. 
ARAUJO, Leonardo. Conar analisa se campanha da Hope incentiva a chantagem. Adnews, [s.1.], 02 mai.2016. Disponível em: https://adnews.com.br/conar-analisa-se-campanha-dahope-incentiva-a-chantagem. Acesso em: 22 out. 2019.

CONAR PEDE suspensão e mudança de campanhas para Gallo e Apas. Propmark, [s.1.], 09 mar. 2012. Disponível em: https://propmark.com.br/mercado/conar-veta-apas-e-pedealteracao-para-gallo. Acesso em: 20 out. 2019.

CONSELHO NACIONAL DE AUTORREGULAMENTAÇÃO PUBLICITÁRIA. CONAR. 2020. Disponível em: http://www.conar.org.br/. Acesso em: 12 out. 2019.

DEPOIS de papel higiênico preto gerar polêmica, Neogama e Personal se retratam. Adnews, [s.1.], 24 out. 2017. Disponível em: https://Adnews.com.br/social-media/depois-de-papelhigienico-preto-gerar-polemica-neogama-e-personal-se-retratam. Acesso em: 23 out. 2019.

FLICK, Uwe; GIBBS, Graham. Análise de Dados Qualitativos. Porto Alegre: Artmed, 2009.

HALL, Stuart. Da diáspora: Identidades e mediações culturais. Belo Horizonte: Editora UFMG; Brasília: Representação da UNESCO no Brasil, 2003.

HOPE se defende: seria absurdo desvalorizar a mulher. Adnews, [s.1.], 02 mai. 2016. Disponível em: https://Adnews.com.br/adpublicidade/hope-se-defende-seria-absurdodesvalorizar-a-mulher. Acesso em: 22 out. 2019.

LEITE, Renata. Skol e Durex causam polêmica no carnaval. Mundo do Marketing, [s.1.], 12 fev. 2015a. Disponível em: https://www.mundodomarketing.com.br/ultimasnoticias/32854/skol-e-durex-causam-polemica-no-carnaval.html. Acesso em: 20 out. 2019.

Skol altera campanha de carnaval após polêmica. Mundo do Marketing, [s.1.], 13 fev. 2015b. Disponível em: https://www.mundodomarketing.com.br/ultimasnoticias/32871/skol-altera-campanha-de-carnaval-apos-polemica.html. Acesso em: 20 out. 2019.

MACEDO, Paulo. Perdigão deixa SunsetDDB e abre concorrência de publicidade.

Propmark, [s.1.], 04 fev. 2019. Disponível em:

https://propmark.com.br/anunciantes/perdigao-deixa-sunsetddb-e-abre-concorrencia-depublicidade. Acesso em: 22 out. 2019.

MARCA de móveis ironiza acusações de machismo. Adnews, [s.1.], 16 dez. 2016. Disponível em: https://Adnews.com.br/internet/marca-de-moveis-ironiza-acusacoes-de-machismo. Acesso em: 23 out. 2019.

MONTEIRO, Thaís. Campanha de Natal da Perdigão é alvo de críticas. Meio \& Mensagem, [s.1.], 27 nov. 2018. Disponível em:

https://www.meioemensagem.com.br/home/comunicacao/2018/11/27/campanha-de-perdigaopara-natal-e-alvo-de-criticas.html. Acesso em: 22 out. 2019.

MORAES, Roberta. Marcas no centro de polêmicas. Qual o preço de se posicionar?. Mundo do Marketing, [s.1.], 07 jul. 2015. Disponível em: 
https://www.mundodomarketing.com.br/reportagens/relacionamento/33953/marcas-nocentro-de-polemicas.html. Acesso em: 21 out. 2019.

MOREIRA, Sônia V. Análise documental como método e como técnica. In: DUARTE, Jorge; BARROS, Antonio. Métodos e técnicas de pesquisa em comunicação. São Paulo: Editora Atlas, 2005.

OLIVEIRA, Priscila. Sanofi retira campanha da Novalfem do ar. Mundo do Marketing, [s.1.], 12 jun. 2015. Disponível em: https://www.mundodomarketing.com.br/ultimasnoticias/33761/sanofi-retira-campanha-da-novalfem-do-ar.html . Acesso em: 20 out. 2019.

PETERMANN, Juliana. Do sobrevôo ao reconhecimento atento: a institucionalização da criação publicitária, pela perspectiva do Habitus e dos capitais social, cultural e econômico. Tese (Doutorado em Comunicação) - Unidade Acadêmica de Pesquisa e Pós-graduação, Universidade do Vale do Sinos. São Leopoldo, RS. p. 408. 2011. Disponível em: http://www.repositorio.jesuita.org.br/handle/UNISINOS/3041. Acesso em: 21 abr. 2019.

PIEDRAS, Elisa Reinhardt; WOTTRICH, Laura. Consumo midiático e recepção de publicidade. In: JAKCS, N (org.) Meios e audiências III: reconfigurações dos estudos de recepção e consumo midiático no Brasil. Sulina, 2017.

PIEDRAS, Elisa Reinhardt. Fluxo publicitário: anúncios, produtores e receptores. Porto Alegre: Sulina, 2009.

. Recepção, circulação e dispositivos sociais de crítica midiática: apontamentos para o estudo das práticas do receptor-consumidor-cidadão diante da publicidade. In: XX Encontro da Compós, 2011, Porto Alegre. Anais... Porto Alegre: COMPÓS, 2011. Disponível em: http://www.compos.org.br/data/biblioteca_1717.pdf. Acesso em 23 out. 2019.

Representaciones, estereotipos y diversidad en la publicidad y propaganda: perspectivas teórico-metodológicas. In: BONIN, Jiani Adriana; GARCÍA, Nicolás Lorite; MALDONADO, Alberto Efendy (org.) Publicidad, propaganda y diversidades socioculturales. $1^{a}$ edição. Quito: CIESPAL, 2016, p.333-349.

RIACHUELO comenta acusação de racismo em propaganda. Adnews, [s.1.], 02 mai. 2016. Disponível em: https://Adnews.com.br/adpublicidade/riachuelo-comenta-acusacao-deracismo-em-propaganda. Acesso em: 23 out. 2019.

SACCHITIELLO, Bárbara. Conar adverte Gabriela Pugliesi e Desinchá por post no Stories. Meio \& Mensagem, [s.1.], 20 fev. 2019a. Disponível em: https://www.meioemensagem.com.br/home/comunicacao/2019/02/20/conar-adverte-gabrielapugliesi-e-desincha-por-post-no-stories.html Acesso em: 20 out. 2019.

. Por que a Renault tirou sua campanha do ar. Meio \&

Mensagem, [s.1.], 01 set. 2017. Disponível em: https://www.meioemensagem.com.br/home/comunicacao/2017/09/01/por-que-a-renault-tirousua-campanha-do-ar.html. Acesso em: 21 out. 2019. 
WOTTRICH, Laura Hastenpflug. A publicidade em xeque: práticas de contestação dos anúncios. Porto Alegre: Sulina, 2019.

\section{Enéias Brum}

Graduado em Relações Públicas (UFRGS), mestre em Comunicação (PPGCOM/UFRGS) e doutorando em Comunicação Social (PUCRS). Integrante dos grupo de pesquisa Comunicação e Práticas Culturais (PPGCOM/UFRGS), no âmbito do projeto "Rumos da pesquisa em publicidade", e do grupo de pesquisa Inovação nas Práticas Publicitárias (INOVAPP - PPGCOM/PUCRS).

\section{Elisa Reinhardt Piedras}

Graduada em Publicidade e Propaganda (UCPel) e em Design Gráfico (UFPel), mestre em Comunicação e Informação (PPGCOM/UFRGS), doutora em Comunicação (PUCRS). Professora e pesquisadora na Faculdade de Biblioteconomia e Comunicação e no Programa de Pós-Graduação em Comunicação (UFRGS). Coordenadora do Projeto "Rumos da pesquisa em publicidade" e autora dos livros "Fluxo publicitário", "Meios e Audiências I e III", além de artigos em periódicos.

\section{(9) $\odot \Theta^{\circ}$}

Esta obra está licenciada com uma Licença

Creative Commons Atribuição-NãoComercial-CompartilhaIgual 4.0 Internacional 